\title{
Information Environment of Digital Humanities: Analysis of Information Interactions
}

\author{
Galina V. Mozhaeva, Polina N. Mozhaeva Renha \\ and Ulyana S. Zakharova* \\ Tomsk State University \\ 36 Lenin Ave., Tomsk, 634050, Russia
}

Received 12.01.2016, received in revised form 22.02.2016, accepted 14.04.2016

The article presents the results of research of the information environment of Digital Humanities (hereinafter-DH) based on the identification of DH structures, directions of their activities and the analysis of the information interactions in the DH sphere. The results of the research help to define key tendencies in the development of DH and the influence of this discipline on the development of the modern Humanities. It is shown that the development of the network infrastructure of DH is accompanied by the expansion of the information interactions representing linear, interactional and transactional communication structures. The article also analyzes types of these interactions, key participants and communication channels, subject matter, indicators of intensity and effectiveness.

Keywords: Digital humanities, information interactions, information environment, information technologies in the Humanities research.

DOI: 10.17516/1997-1370-2016-9-7-1572-1585.

Research area: culture studies.

\section{Introduction}

The discipline of Digital Humanities has occurred a little more than a decade ago, but so far in science there is no unambiguous definition for it, and one of the most relevant tasks is to understand the DH content, identify the position of this discipline in the system of the Humanities, and discuss the prospects for its development.

Today, Digital Humanities is regarded as one of the many variants of identification of the Humanities emerging in the information society and/or on the basis of information and communication technologies.
One of the first attempts to present a systematic understanding of the content, problems and prospects of the development of Digital Humanities was "The Manifesto for the Digital Humanities" published in May 2010 by Marin Dacos, Professor of History, Director of the Centre for Open Electronic Publishing (France). The Manifesto emphasizes that digital research methods are important for all the Humanities and rely on scientific paradigms accumulated by each of the relevant disciplines using the tools and perspectives opened up by digital technologies. "Digital Humanities are interdisciplinary by

(c) Siberian Federal University. All rights reserved

* Corresponding author E-mail address: mozhaeva@ido.tsu.ru; pmozhaeva@gmail.com; zakharova@ido.tsu.ru 
definition and carry all of the methods, tools and perspectives of knowledge related to digital technologies in the Humanities". According to the authors of the Manifesto, the DH courses should be included in all training programs in the Humanities and social disciplines, arts and literature ${ }^{1}$.

Manfred Thaller, Professor of the Department of Information Technologies in Historical and Cultural Studies at the University of Cologne (Germany), carried out the analysis of the current status of the interdisciplinary field of DH in his work "Controversies around the Digital Humanities". He saw "dangers" in the development of Digital Humanities: focus on a research infrastructure at the expense of the analytical methods and tools; narrowing of $\mathrm{DH}$ possibilities to the use of information technologies in specific areas of the Humanities; a threat of an impending "mobile revolution" that may lead to the "repetition of the destructive process that occurred in the course of the PC and Internet revolutions"; a potential possibility for $\mathrm{DH}$ "to play a more active role not only in the perception of technologies, but also in their development" (Thaller, 2012).

According to the experts of the UCLA (University of California), digital humanities is the natural continuation and extension of the traditional sphere of the Humanities, and not a substitute for the traditional Humanities needs. DH interpret the cultural and social impact of the new media and information technologies, create and apply these technologies in order to respond to the traditional and cultural, social, historical and philological questions emerged due to a new information era: "The role of humanists is very important at this historical moment, since our cultural heritage has migrated to digital formats, and our attitude to knowledge, cultural materials, technology and society has changed dramatically ${ }^{2}$."
M. Thaller divided the DH sphere into key areas related to 1) the analysis of the text by the use of various computer means from indexing to formalized determination of the author's style, 2) the use of texts or images for obtaining new information ("facts") and the further analysis of the complex of these "facts" (database, statistical analysis methods, geographic information systems, geospatial modelling, etc.) in history, anthropology, archaeology, art history that deal with social phenomena or material objects, 3) non-textual resources, including digitization of large collections of images, their control, the use of three-dimensional models of artefacts, visualization of search requests in databases. When asked whether DH is just a consumer of the developments in the field of technologies or it is able to influence the further development of the technologies themselves, M. Thaller noted that it is important that "conceptual solutions on the use of new technologies in the Humanities are defined by the concept of the Humanities" (Thaller, 2012).

In Russia, a stable interest among researchers in a new field was designated as part of the Association of History and Computer, which is reflected in particular in the program of the International Conference "Historical studies in the digital era: information resources, technologies, methods" (Moscow, 3-5 October, 2014), during which the problems and prospects of DH were discussed at the plenary session in the report by Professor K. Schurer (University of Leicester, United Kingdom) "History and Computing or Digital Humanities? Which Way to the Future?" (Schurer, 2014: 4-8), during the Round Table "Digital Humanities: discussion questions", at the section "Methodological problems of historical information" (Volodin, 2014: 14-16).

Recent works in the DH sphere published in 2015-2016 have placed emphasis in research priorities in this discipline. They are devoted 
to such issues as the use of advanced tools of the text analysis to identify the latent content and the attitude of research subjects to different situations, visualization of sound topology of poems and data visualization to enhance cognitive abilities, data management tools for writing scientific theses, the study of the creative process of the software developers and theatrical production, etc.

In recent years Digital Humanities has become perhaps the most dynamic area of the Humanities development on the background of the overall Humanities crisis and the collapse of the Humanities studies in universities and academic centres around the world. This is due not only to the transformation process in the Humanities studies, but also to the significant progress in algorithms and computational tools used for complex data, as well as social networks through a new understanding of language, culture and history.

The use of modern technologies and the appeal to the natural-scientific and mathematical knowledge increase the DH status in the scientific community and expand opportunities for the dynamic development of this discipline. At this, Digital Humanities are seen as natural continuation and expansion of the traditional sphere of the Humanities, and not as replacement or refusal from the traditional Humanities demands.

Development of the DH network infrastructure is accompanied by the expansion of information interactions between the experts from different centres for Digital Humanities in the world.

DH introduced the intercultural information interactions understood as communications between carriers of different cultures, which can be implemented both actually, in person at international conferences, workshops, seminars, etc., and virtually, through the
Internet technologies (video presentations, webinars, forums, social networks, blogs, etc.). Communication interactions through virtual research environments, communities, networks and associations, thematic online resources, services and platforms, video conferences, webinars via e-mail, social networks, Skype, blogs, forums, publications and discussions in the digital media are widespread in the $\mathrm{DH}$ sphere. Their study allows us to reconstruct the information environment of DH and indentify the development perspectives of this interdisciplinary field.

\section{Conceptological grounds of the study}

The study is based on a process-information approach to communication and understanding of the information interaction as communication, whichallows us toapply threebasic communication structures in relation to information interactions in DH (Gavra, 2011: 93-95):

1) linear (one-way interaction without feedback), including newsletters, fax messages, printed publications, magazines on Digital Humanities, posting materials in electronic archives, collections and libraries;

2) interactional (interaction between a source and a recipient of the information), including presentations at conferences, master classes, webinars, regular educational process, training camps, electronic publishing and discussion in the digital mass media, blogs, creating and launching themed online resources, services and platforms for the Digital Humanities on the Internet;

3) transactional (constant equal dialogue, in which all the interacting subjects alternately act as sources and information recipients), including group discussions, round tables at conferences, in camps, in project groups, forums, meetings of researchers, exchange of letters, communication 
via Skype, social networks, in virtual research environments.

In order to determine a structure of the act of information interaction in Digital Humanities, let us apply the classical model of communication by $\mathrm{H}$. Lasswell, which helps to describe any information interaction by a simple technological model: communicator - message - means (channel) - recipient - effect (Lasswell, 2011: 37-51).

\section{Introduction into the problem}

This study aims to identify the specifics of the information environment of Digital Humanities, its components and information interactions emerging in it, in order to identify key trends in the development of DH and the impact of this discipline on the development of the modern Humanities. The analysis of the main types of information interactions, their main participants and communication channels reveals the intensity and efficiency of the DH development, the impact of information interactions on the development of the DH network infrastructure.

\section{Methods}

The article is based on the source analysis of the Internet resources of periodicals and organizations, identification and comparison of the qualitative and quantitative indicators in synchrony and diachrony, scientometric analysis of publications in scientific journals and collections of conference materials, methods for visualization of information on publications and DH centres, as well as the generalization of the obtained results.

In order to establish the authenticity of the collected empirical materials, the authors conducted verification of the information sources revealed as a result of the Internet search queries, which include the official sites of scientific and educational organizations, articles and reviews that have authors and have been posted on the official websites of the reviewed publications and scientific and educational organizations. Verification of information sources included comparing information from several independent sources. The comparative analysis used such techniques as the analysis of integrity and completeness of information, the analysis of spatial and temporal correlations.

Reliability and authenticity of the identified sources of information are provided by theirofficial character. Reliability of the sources is verified by the authority of a press organ, publishing house, web site, etc.; authenticity - by a guarantee of originality of information fixation in the form of a digital document or a digital copy of the printed text of scientific publications with their filters of editorial selection, review, responsibility of the author and editor, reputation, etc.

The data obtained as a result of information search are processed using statistical methods, systematized and are a basis for the study of information interactions and reconstructions of the DH information environment.

\section{Discussion}

The study of the DH environment is based on the analysis of the nature of information interactions occurring in the DH sphere and forming its information environment. The identified information interactions are classified as linear, interactional and transactional communication structures in the context of a process-information approach to communication and are analyzed in the framework of the classical communication model by H. Lasswell.

\section{Linear communication structures in $\mathrm{DH}$}

Linear communication structures in DH include personal subscription to Digital Scholarship in the Humanities (formerly LLC), 
Digital Medievalist (International online community of medievalists working with digital content), papers published in the Humanist magazine and articles published in various scientific journals.

The growing number of blogs and magazines on $\mathrm{DH}$, as well as subscribers to the relevant publications is an indicator of the intensity and efficiency of information interactions in this field. The number of followers of @DHQuarterly (electronic journal "Digital Humanities Quarterly") on Twitter increased from 688 people in $2011^{3}$ to 6,550 people in February 2016"; the number of followers of @DHNow (Digital Humanities Now) increased from 2,794 people in $2011^{5}$ to 22.5 thousand in February 2016 . Thus, the overall number of followers increased about by 10 times in 5 years.

The rapidly growing interest in this topic is also indicated with the help of the bibliometric analysis of publications devoted to the $\mathrm{DH}$ problems that were published over the past 10 years in journals indexed in major databases of science citation that are Scopus ${ }^{7}$ of the publishing house Elsevier and Web of Science ${ }^{8}$ (hereinafter WoS) maintained by Thomson Reuters.
In Scopus, 361 results with the exact phrase "Digital Humanities" in a title, abstract or keywords were found in the query of original research works and reviews for 2005- 2015 (Fig. 1). The quantitative analysis revealed a gradual increase in the number of both original research works and bibliographic reviews. A certain decline in publication activity observed in Fig. 1 is due to a time delay between the release of the publication and the moment of its indexing. The peak of growth is 2013 .

Since 2011, not only the number of authors has rapidly increased, but also citations, which is one of the key indicators of the relevance of scientific research today. Fig. 1 shows citation indexes of publications of interest to us except for self-citation. Distribution of publications by affiliation of the authors helps to determine the tendency for inclusion of the growing number of organizations - universities, institutes, research centres, etc. in the Digital Humanities problematics. Thus, in January 2016, 6 publications devoted to $\mathrm{DH}$ and prepared by 16 authors were published.

The United States of America is the leader in the number of publications devoted to $\mathrm{DH}$.

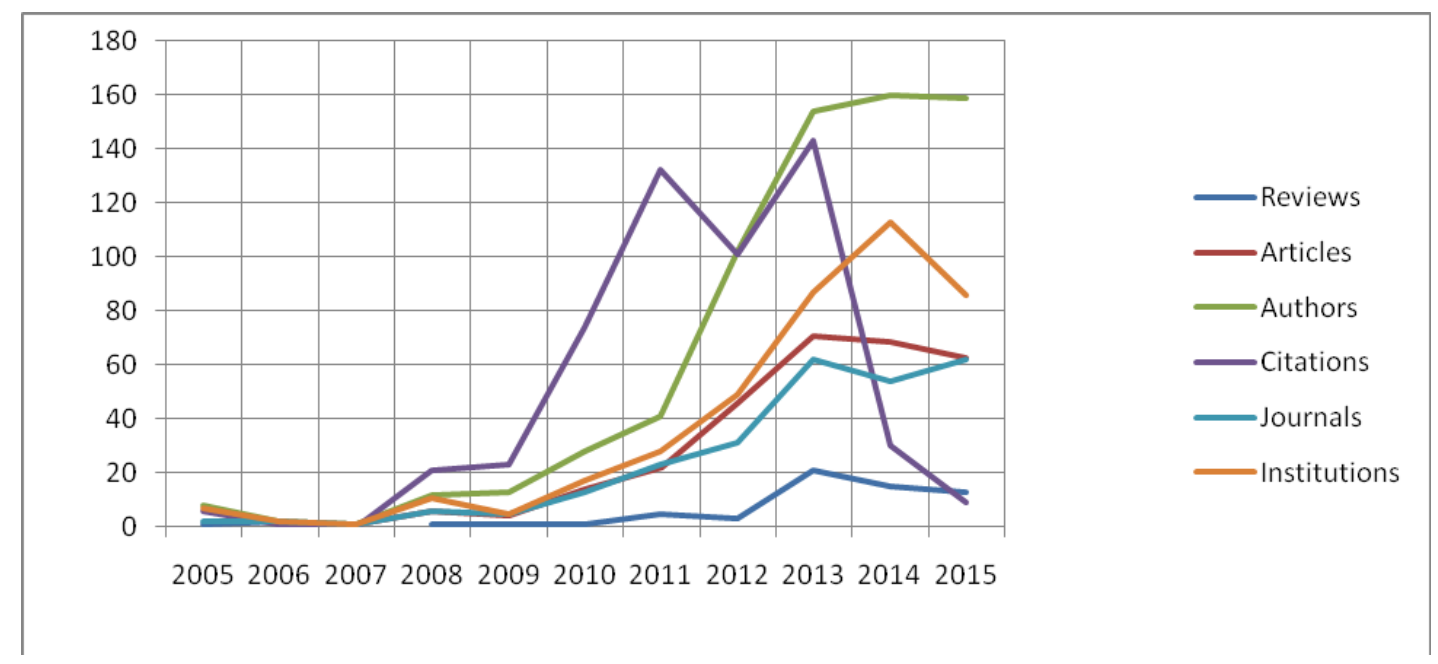

Fig. 1. Data on the DH publications in scientific journals indexed in Scopus (2005-2015) 
American scientists were the first ones who began studying DH; they annually publish the majority of works on the subject of DH. The second largest number of publications was written by scientists from the UK, the third - from Germany. British and German researchers, as well as the Americans, have engaged themselves in the development of the DH discipline and continue to actively publish their works. However, there are countries in which the research has begun relatively recently, but maintains fairly active; these are Australia, Spain, Sweden and Austria (Fig. 2 and 3).

A search for scientific publications on the topic of "Digital Humanities" in the WoS database revealed 309 results. Fig. 4 shows a general trend towards an increase of quantitative indicators of these publications, except for citations.

As in the Scopus database, in the WoS the largest number of scientific publications accounts for American researchers, which confirms direct connection between the duration of the development of the subject and the number of published scientific papers on it. However, according to the diagrams in Fig. 5 and 6, there are exceptions to this rule. Thus, representatives of Venezuela and Singapore who have published their works shortly after the first American works have not become leaders in this field, but researchers from Australia, Italy and Spain, by contrast, who began publishing the results of their works in the field of DH in journals indexed in WoS only in 2012-2013, by the number of publications already achieved a level of the French who published the results of their research in the field of DH back in 2010.

Besides the already mentioned linear communication structures, we should note the increasing number of electronic archives, collections and libraries, as well as the development and expansion of virtual research environments and platforms. Examples include the experimental Pegasus Data Project platform ${ }^{9}$ or the Digital Research Infrastructure for the Arts and Humanities (DARIAH) ${ }^{10}$, designed to facilitate access and use of all digital research data on the European arts and the Humanities.

The classical model of communications by H. Lasswell applied to the listed linear structures of communication allowed us to identify the main elements:

- communicators and recipients of information are the representatives of the professional community of $\mathrm{DH}$ and other scientific areas (individuals and organizations), undergraduate and graduate students studying at $\mathrm{DH}$ programs, representatives of the general public in the Humanities;

- a message/theme - results of the DH studies, research presentations, discussion of published papers, DH news, etc.;

- communication channels - printed and electronic journals, databases of science citation, newsletters, electronic educational resources, etc.;

- the effect of linear communications is in provision of information on the results and trends in the DH research, collection of data for new research works, involvement in the discussion, etc.

\section{Interactional communication structures} in $\mathrm{DH}$

Interactional communication structures in Digital Humanities are presented by the sessions of the Modern Language Association and The European Association for Digital Humanities (EADH) (from 1973 to 2012 - Association for Literary and Linguistic Computing) ${ }^{11}$, Day of the DH participants, as well as by presentations at conferences dedicated to $\mathrm{DH}$.

In recent years, there has been growth in the number of ongoing local and international seminars and conferences on $\mathrm{DH}$. 


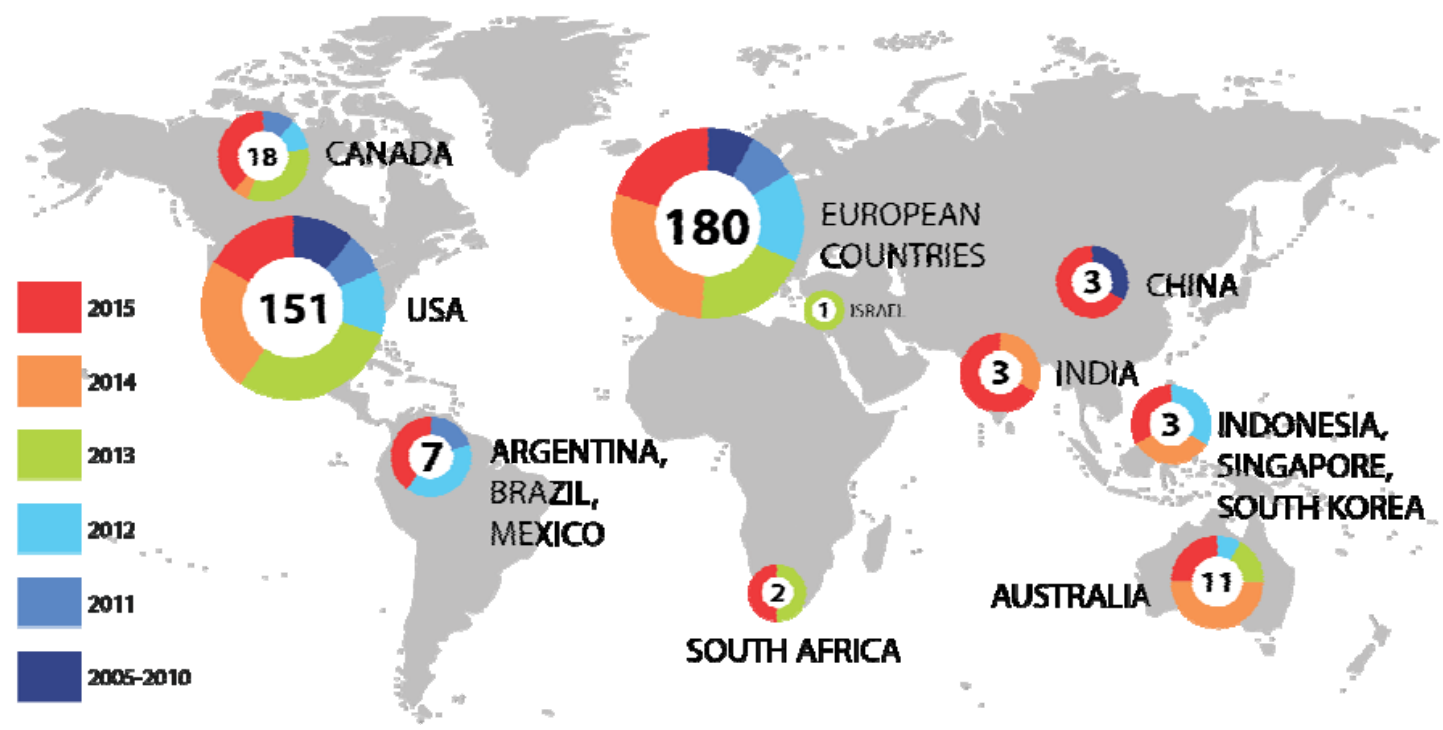

Fig. 2. Geographical distribution of publications in the field of DH in scientific journals indexed in Scopus (2005-2015)

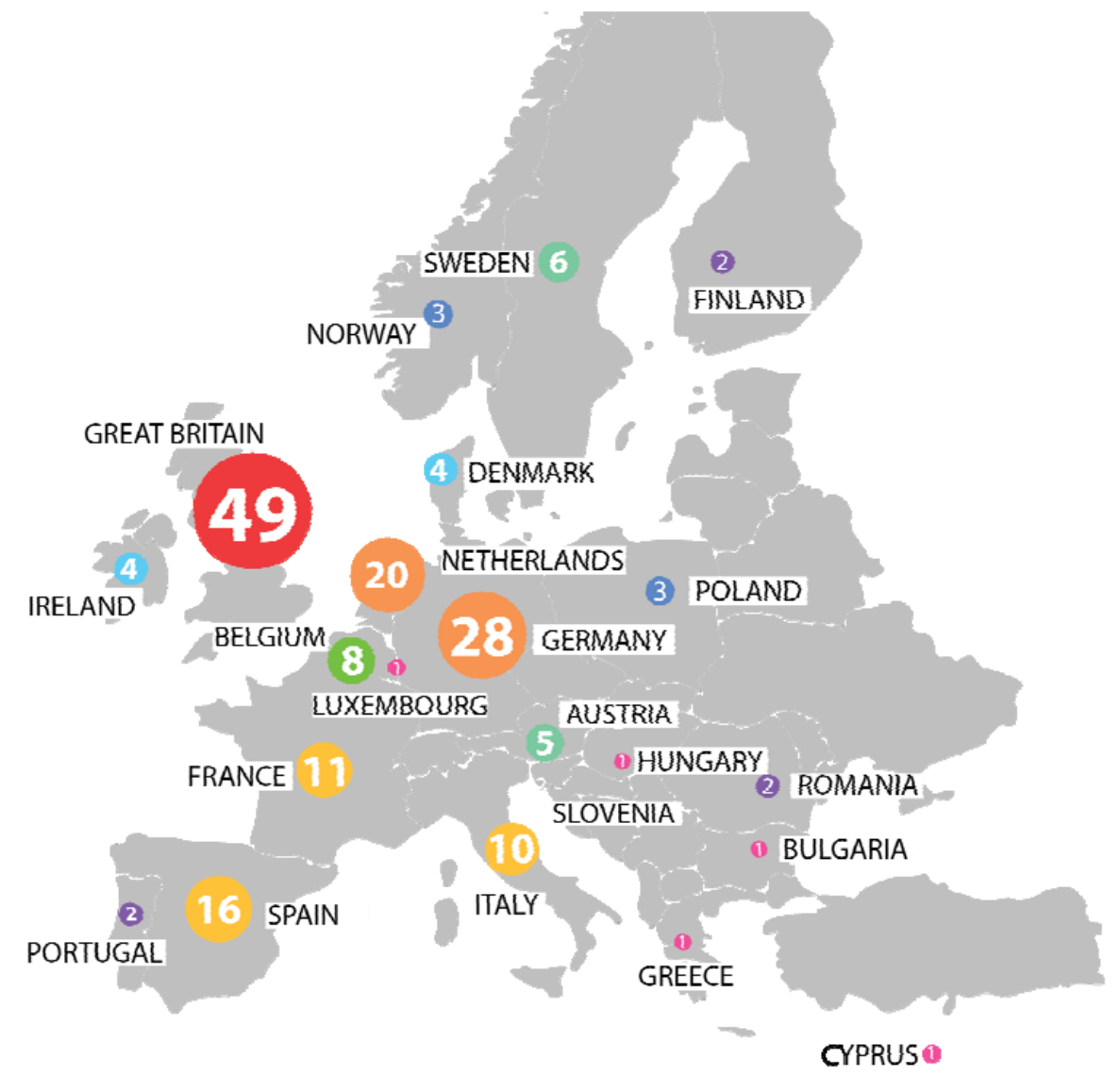

Fig. 3. Geographical distribution of European publications in the field of DH in scientific journals indexed in Scopus (2005-2015) 


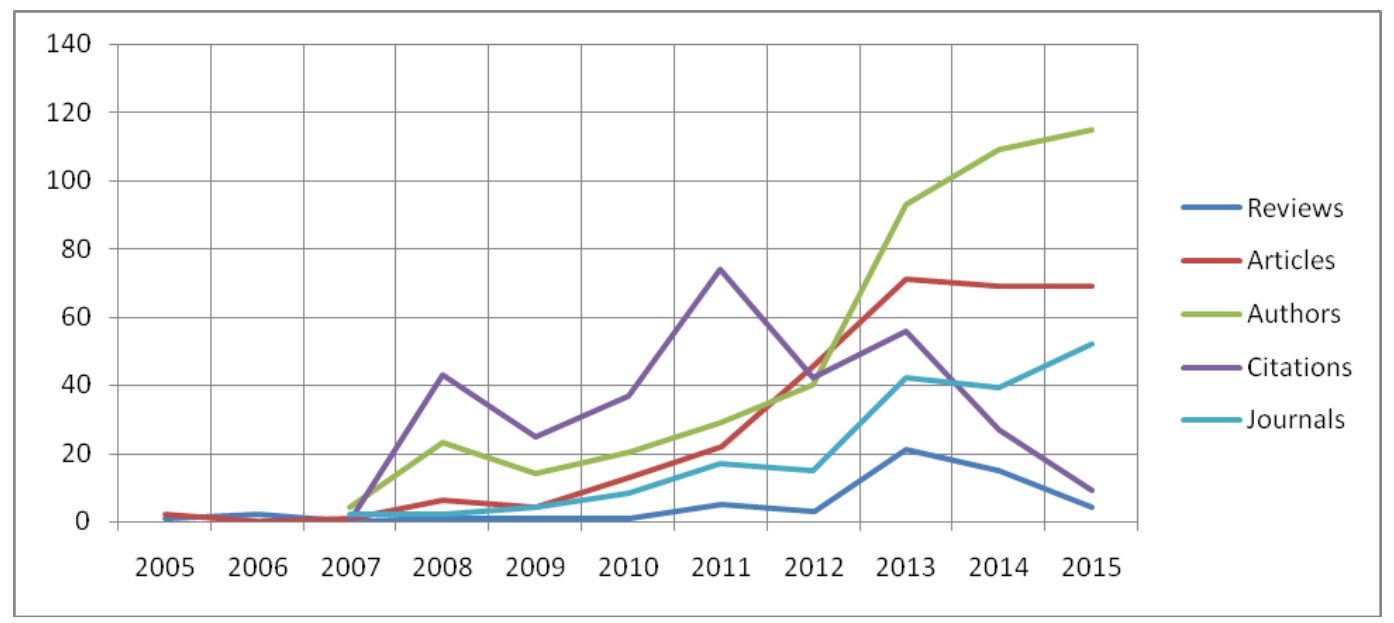

Fig. 4. Data on the DH publications in scientific journals indexed in WoS (2005-2015)

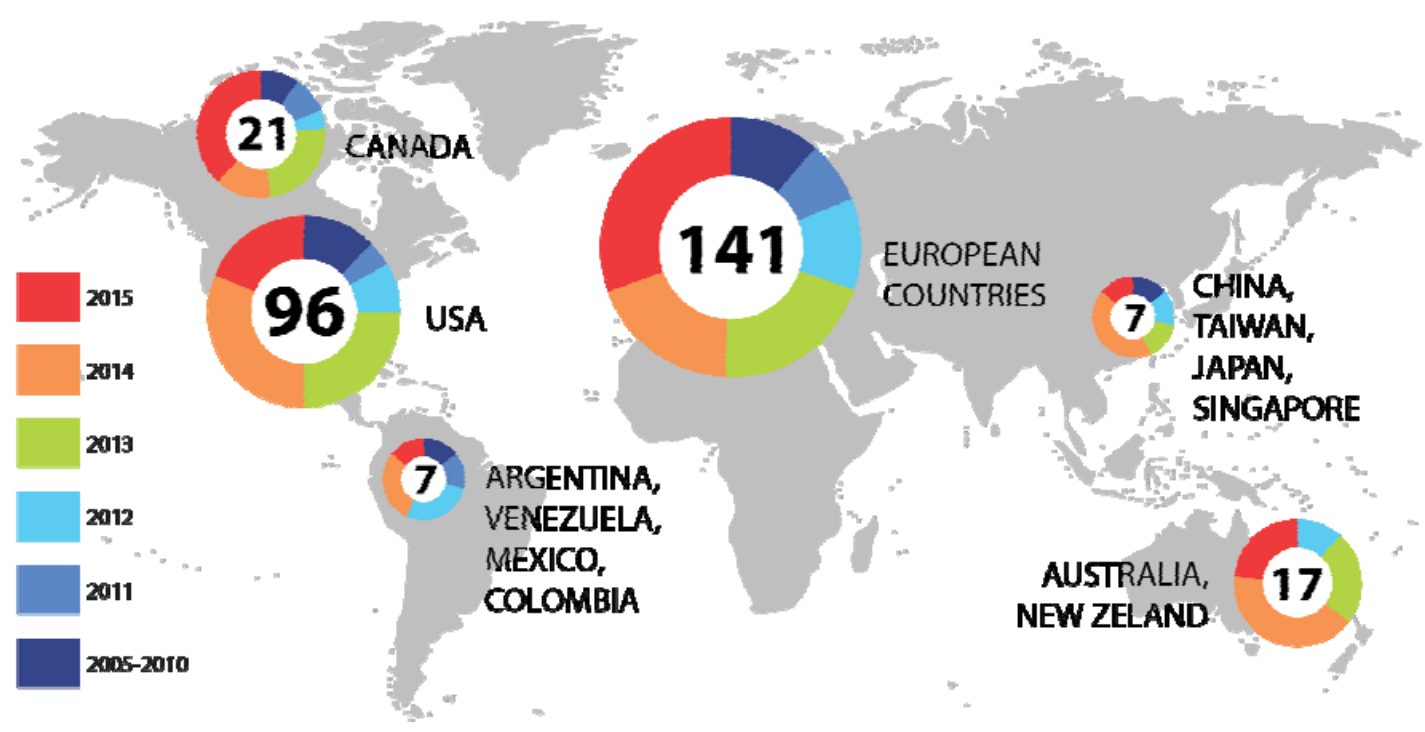

Fig. 5. Geographic distribution of publications in the field of $\mathrm{DH}$ in scientific journals indexed in WoS (2005-2015)

The largest and most significant conference in this area is the Digital Humanities Conference ${ }^{12}$ held by the Alliance of Digital Humanities Organizations (ADHO), which is composed of the above-mentioned EADH, the DH community of Canada, Australia and Japan, as well as the Association for Computers and the Humanities and centerNet (international network of DH centres) ${ }^{13}$. Since the first joint conference in 1989 at the University of Toronto in Canada, it has annually been held at universities of Mexico, Poland, Australia, Switzerland, the USA, Sweden, Hungary and other countries.

The search for publications of the conference proceedings in such largest databases of scientific citation as Scopus (Fig. 7) and WoS (Fig. 8) has revealed 223 and 78 results respectively. Queries were formulated just like in the search for articles, but further the document type was specifiedconference proceedings. The bibliometric 


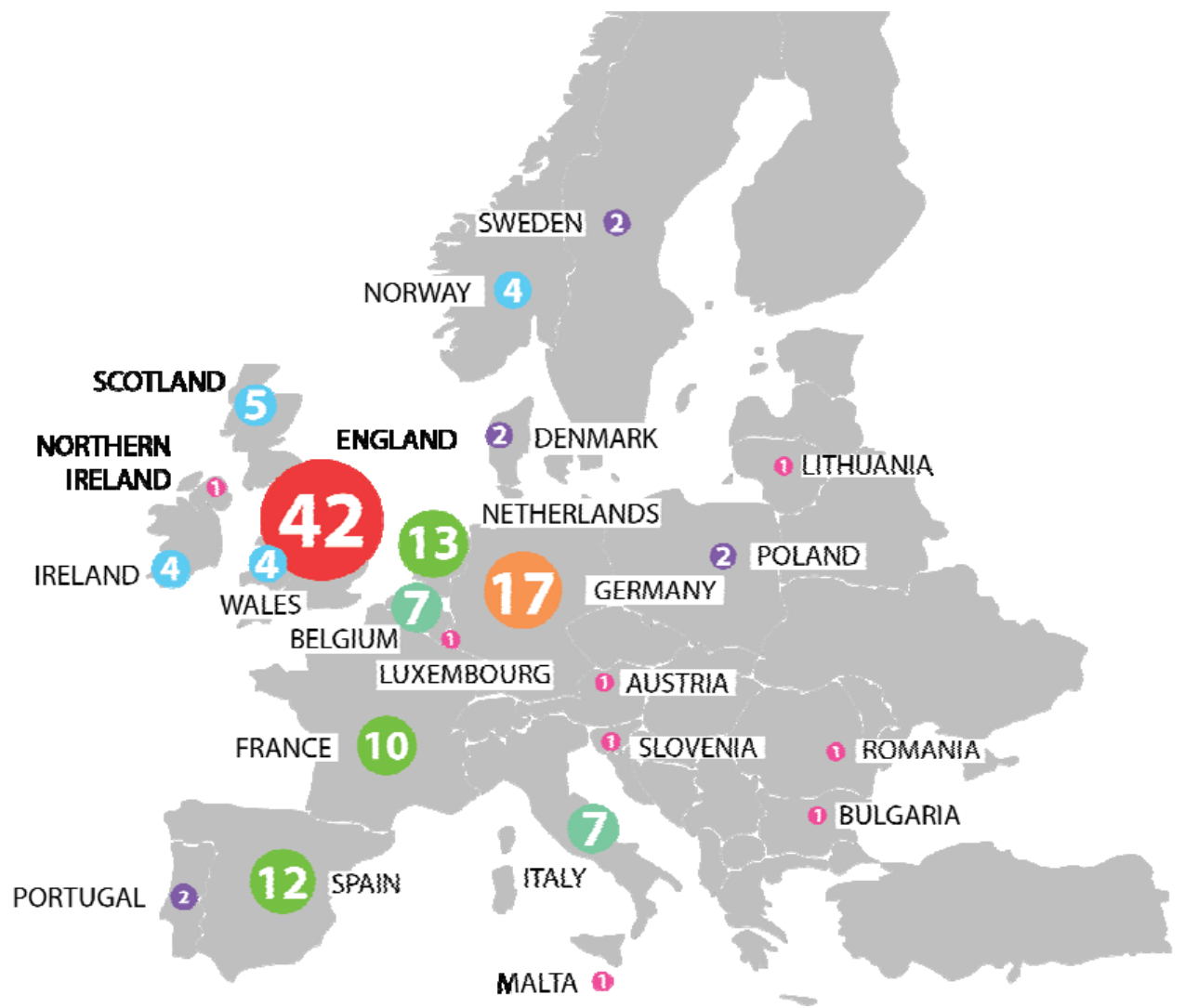

Fig. 6. The geographical distribution of European publications in the field of DH in scientific journals indexed in WoS (2005-2015)

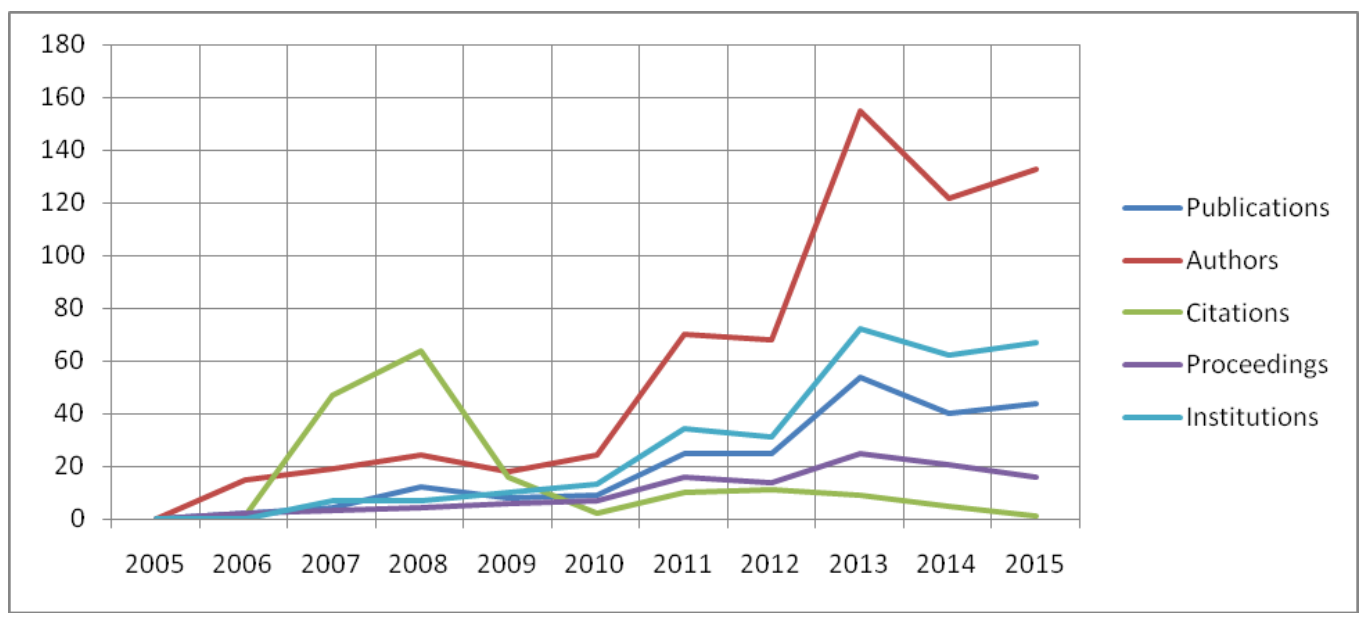

Fig. 7. Data on the conference proceedings in the field of DH published in Scopus (2005-2015)

analysis of these publications showed that their growth in the last decade gave way to recession in 2014-2015. This can partly be explained by the desire of the authors to present the results of their research in the cited publications - ranking scientific journals.

Application of the communication model by $\mathrm{H}$. Lasswell to interactional communications 


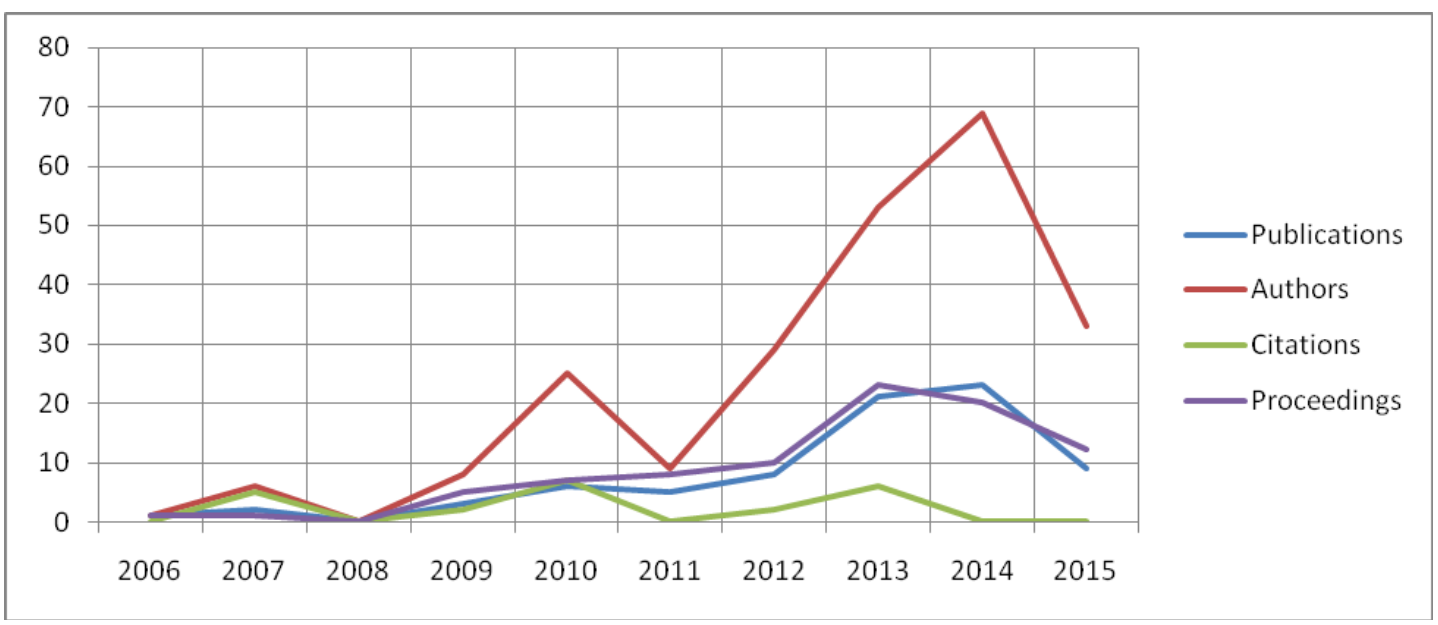

Fig. 8. Data on the conference proceedings in the field of DH published in WoS (2005-2015)

structures in the field of $\mathrm{DH}$ allowed allocating their basic elements:

- communicators and recipients of information are a professional community of $\mathrm{DH}$, PhD students studying at DH programs;

- a message/theme is a discussion of the course and results of the latest, most current research works and development issues of $\mathrm{DH}$ as a whole;

- communication channels - group discussions, lectures and presentations at conferences;

- the effect of interactional communications is in identification of the problem areas of DH, formulation of new ideas, development of research projects, creation of new research teams and others.

\section{Transactional communication structures in $\mathrm{DH}$}

Transactional communications structures in DH include: discussion list "Antiquist, a heritage computing community" (Digital Heritage Community), "THATcamps - The Humanity and Technology Camps" (Humanities and Technology) and DH centres.

We consider the growing number of $\mathrm{DH}$ centres and a qualitative change in their activity as a proof of the dynamic development of this field. In the course of our investigation as a result of processing more than 4000 Internet search query results and data of the published works, we selected 430 research and educational institutions from 42 countries working in different areas of the Humanities and positioning their belonging to DH. The search queries were formulated in English, French, Portuguese, Spanish, German, Russian, Japanese, Chinese, Korean, Malay and Arabic. Linguistic diversity is due to the fact that, according to a preliminary study, many of the DH structures are represented only in the national Internet space.

The analysis of the verified empirical data revealed organizational forms of the research and education centres working in $\mathrm{DH}$, identified the main directions of research in this field in the world's leading centres, and located these centres by attaching them to the world map: http://huminf. tsu.ru/nir/dh/map.htm

The dynamics of creating the DH structures shows that about $20 \%$ of them have been created in the 1960-80's at the major universities as centres for the Humanities research that were positioned as DH structures in 1990-2000. About $25 \%$ of the studied structures have been created in the 1990 's, $39 \%$ - in the 2000 's, $16 \%$ - in the 
2010's. A steady increase in the number of DH structures is observed since the mid 2000's. In the 2010's there is active institutionalization of DH: permanent structures, educational and research units (centre, laboratory, institution, department, chair, school) at major universities, research institutions, etc. are being established. Among the studied 430 structures of DH such structures amount to more than $75 \%$. At the same time, the number of temporary structures and teams (projects, groups, initiatives, etc.) created to solve specific problems is reducing.

There is a growing attention to the educational activities in the field of DH (masters and postgraduate programs, short-term training and courses), which is typical for $26 \%$ of the studied DH structures. The applied developments are becoming more and more important:

- $22 \%$ of the studied structures develop and introduce new digital tools, methods and models;

- $27 \%$ of structures provide a variety of digital resources, services and platforms, mobile applications, multimedia systems, 3D-models, GIS objects, etc.;

- $7 \%$ of structures develop online tools for learning.

The analysis of the main directions of scientific and educational activities in the field of DH found that most of the studied structures conduct interdisciplinary research, promote the use of digital technologies for the Humanities research, consult and provide technical assistance to humanists, regularly conduct seminars and workshops on the DH subjects. It allocated 18 activities widely used in the structures of DH. It is important to note that in most of the DH structures the focus is not only on the use of digital tools, but also on the study of the results of their application, the impact on the transformation of learning processes in the field of the Humanities and social sciences.
In recent years, we may notice the processes of researcher consolidation and selforganization in the framework of this research field, as well as the development of common principles, methods and scientific digital tools. We revealed 28 network associations (association, network, platform, consortium, alliance) that are both national and international, mostly continental and transcontinental (Mozhaeva, 2015: 10-13).

On the basis of the analysis of the activity of 430 world's DH centres in accordance with the classical communication model by $\mathrm{H}$. Lasswell we identified the basic elements of the external and internal information interactions of these centres.

Both individuals (teachers, researchers, students) and organizations with their structural units (institutes, departments, chairs, centres, laboratories, etc.), as well as network associations - association, community, network, etc. act as communicators and recipients of information in the field of $\mathrm{DH}$ in transactional communications. A recipient of information is also the general public that is not involved in the research activity in the field of $\mathrm{DH}$, but receives information on the results of $\mathrm{DH}$.

The subjects of information interactions (message) include:

- discussion of research works by the areas of activity in the field of DH (data collection, analysis, visualization, study of texts and their computerized analysis, electronic publications, critical editing, management of digital archives, collections, libraries, interaction of human and computer, human and robot, impact of digital technologies on human, digital culture and digital art, digital history, virtual reality and cyber-culture, artificial intelligence and intelligent systems, information society, culture and behaviour, digital games, digital information management, etc.); 
- training in the field of DH (masters and postgraduate programs, short-term training and courses);

- solution of actual problems of the development of $\mathrm{DH}$;

- planning and conducting of activities in the field of DH.

The main channels of transactional communications used in DH include: face-to-face communication, conferences/video conferences, seminars/webinars, round tables, master classes, lectures, "schools", printed magazines, electronic magazines, virtual research environments, electronic archives, collections and libraries, thematic online resources, services and platforms, e-mail, social networks, Skype, forums, telephone, fax. Interactions are carried out both orally and in writing in traditional and digital formats.

The effect of information interactions is different in each case: it may be gaining understanding, fullacceptance, misunderstanding, doubt, scepticism, rejection, consensus-building, profitable cooperation, network projects, etc.

Effectiveness of information interactions in $\mathrm{DH}$ is generally confirmed by the intensive development of this sphere. The number of the $\mathrm{DH}$ centres and educational exchange programs for DH is increasing around the world. If in 2006 the European courses registry for DH DARIAH ${ }^{14}$ recorded only 2 such programs, then in 2015 this figure already reached 71, and by early $2016-152$, including programs for undergraduate, graduate and postgraduate training.

There are regularly organized camps and summer schools on the subject of DH for both students and professionals involved in DH (the DH Summer Institute in Canada (University of Victoria), the European Summer School "Culture \& Technology" in Germany (University of Leipzig), the Oxford Summer School in DH in the UK, Madrid DH Summer School in Spain). The THATCamp format (The Humanities and
Technology Camp) is the most prominent among others - it is a camp on the Humanities and technology positioned as a "non-conference" or an "anti-conference". One of the main key features of THATCamp is the joint work of all its participants, when each participant is engaged in the discussion and work at each session, including establishment of the agenda and the program of activities that are determined by all the camp participants on the first day of its work, and not by the organizing committee a few weeks or months prior, as is usual at conferences ${ }^{15}$. The result of the work in this format becomes the transactional information interaction of participants.

Another important process of the organization of information interactions in $\mathrm{DH}$ is structural consolidation and integration of the $\mathrm{DH}$ centres in the network and association. It can be both highly specialized communities (e.g., Digital Games Research Association, the Society for Digital Heritage and the Virtual Reality Society of Japan) and more large-scale associations united by the theme of $\mathrm{DH}$ in general: the European Association for Digital humanities, the Association for computers and the humanities $(\mathrm{ACH})$, the Canadian society for Digital humanities (CSDH), the international network of centres Digital Humanities centerNet, the Australasian Association for Digital Humanities (AADH), the Japanese Association for Digital Humanities (JADH). Moreover, all the latest structures are combined into a single global Alliance of digital humanities organizations $(\mathrm{ADHO})^{16}$. A similar trend to establish social ties between the DH-organizations is evidence of the desire of the DH researchers to conduct more productive information interactions necessary for the further development of this sphere.

According to the Dutch professors S. Wyatt and A. Scharnhorst, in accordance with the marketing model of the adoption of innovations, DH is now at the stage of adoption of DH by "early 
majority" confidently moving to the moment of adoption by the "late majority"17. Such dynamics is impossible without the effective information interactions, a study of which confirms a thesis on the DH prospects at the present stage of development of the Humanities as one of the most relevant options for the identification of the Humanities emerging in the information society and/or on the basis of information and communication technologies.

\section{Conclusion}

The study of the DH environment based on the study of information interactions occurring in $\mathrm{DH}$ and forming its information environment showed that the analysis of information interactions is one of the most effective ways to study the DH community and determine its effect on the development of the modern Humanities.

The study found that the information interactions in DH represent different communication structures: linear (scientific journals, electronic educational resources and research platforms), interactional (sessions in associations and presentations at conferences), transactional (discussion list, camps, centres for DH). Despite the differences, in all types of communication structures in the past 5 years there has been a quantitative increase and qualitative development of channels, themes, communication participants, which confirms the hypothesis of the research about the formation of the trend towards the expansion and deepening of Digital Humanities as a new scientific field based on interdisciplinarity and application of digital technologies in the Humanities research.

\section{Acknowledgements}

This work is supported by the grant of the Russian Humanitarian Science Foundation No. 14-03-00659 "The humanities in the digital age: from branch informatics to digital humanities".

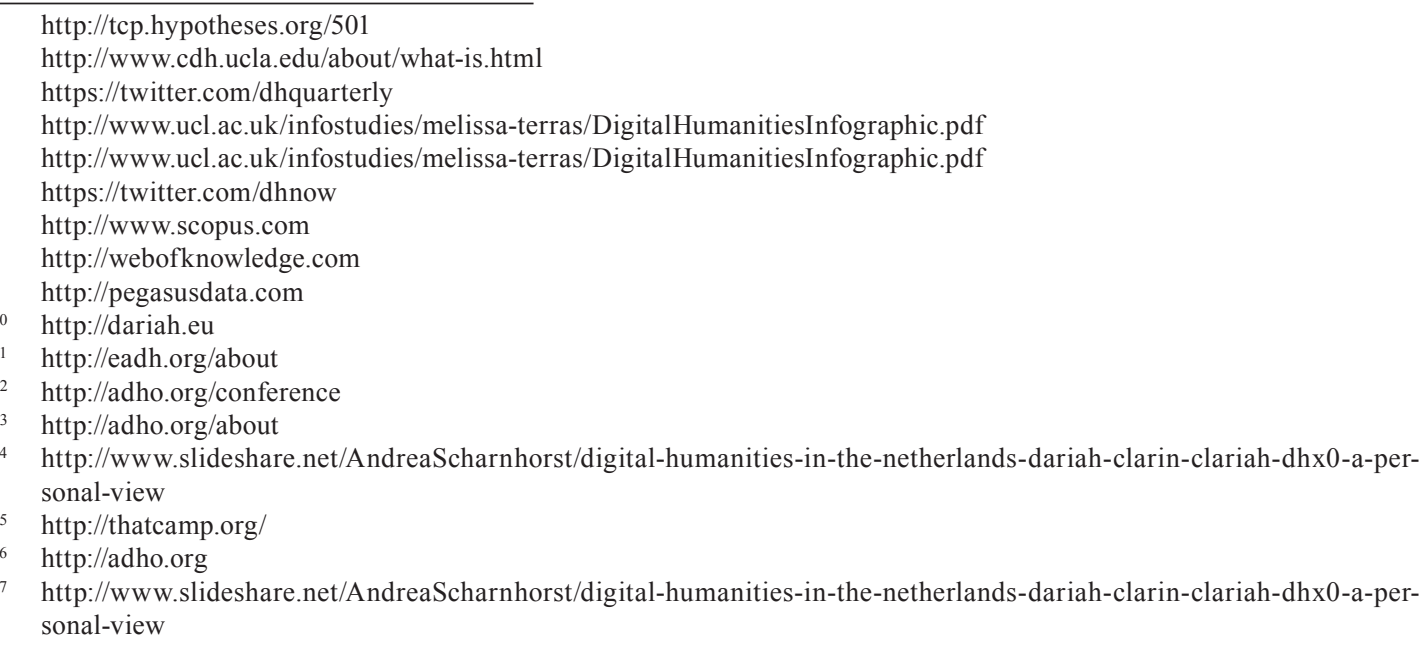

\section{References}

Gavra, D.P. (2011). Osnovy teorii kommunikatsii [Basics of communication theory]. SaintPetersburg, Piter, 284 p.

Lasswell, H. (1948). The Structure and Function of Communication in Society. In The Communication of Ideas. Ed. L. Bryson. New York, Harper and Brothers, 1948. 37-51.

Mozhaeva, G.V. (2015). New Horizons of Digital Humanities in the context of scientific analysis: infrastructure and basic directions of development [Novye gorizonty Digital Humanities v kontekste 
naukovedcheskogo analiza: infrastruktura i osnovnye napravleniia razvitiia. Informatsionnye tekhnologii v gumanitarnykh naukakh]. Tezis nauchno-prakticheskoi konferentsii "Informatsionnye tekhnologii v gumanitarnykh naukakh" [Thesis at the conference "Information Technologies in the Humanities”]. September 21-22, 2015. Siberian Federal University, Krasnoyarsk, 10-13.

Thaller, M. (2012). Diskussii vokrug Digital Humanities [Discussions around Digital Humanities]. In Istoricheskaia informatika. Informatsionnye tekhnologii i matematicheskie metody v istoricheskikh issledovaniiakh i obrazovanii [Historical Informatics. Information technologies and mathematical methods in historical research and education]. 1, 5-13.

Schurer K. (2014). History and Computing or Digital Humanities? Which way to the future? In Informatsionnyi biulleten' Assotsiatsii "Istoriia i komp'iuter [Newsletter of the Association "History and Computer"']. 42, Moscow, 4-8.

Volodin, A.Iu. (2014). Digital Humanities: mezhdisciplinarnost' v tsifrovuiu epokhu [Digital Humanities: interdisciplinarity in the digital era]. In Informatsionnyi biulleten' Assotsiatsii "Istoriia $i$ komp'iuter [Newsletter of the Association "History and Computer"]. 42, Moscow, 14-16.

\title{
Информационная среда Digital Humanities: анализ информационных взаимодействий
}

\author{
Г.В. Можаева, П.Н. Можаева Ренья, У.С. Захарова \\ Наииональный исследовательский \\ Томский государственный университет \\ Россия, 634050, Томск, пр. Ленина, 36
}

В работе представлены результаты исследования информачионной среды Digital Huтапities (далее-DH), основанные на выявлении структур DH, направлений их деятельности и анализе информачионных взаимодействий в сфере DH. Результаты исследования помогают определить ключевые тенденции в развитии DH и влияние этого направления на развитие современных гуманитарных наук. Показано, что развитие сетевой инфраструктуры DH сопровождается расширением информационных взаимодействий, представляющих собой линейные, интеракционные и трансакциионные конструкиии коммуникации. Проанализированы виды этих взаимодействий, основные участники и каналы коммуникаций, тематика, показатели интенсивности и эффективности.

Ключевые слова: иифровые гуманитарные науки, Digital huтапіties, информационные взаимодействия, информационная среда, информационные технологии в гуманитарных исследованиях.

Научная спещиальность: 24.00.00 - культурология. 